\title{
Analgesic Effects of the Polarized Red+Infrared LED
}

\section{Light}

Sergiy Alexandrovich Gulyar ${ }^{1,2}$ and Zynaida Andreevna Tamarova ${ }^{1}$

1. Department of General Physiology of Nervous System, Bogomoletz Institute of Physiology, Kyiv 01024, Ukraine

2. International Medical Innovation Center Zepter, Kyiv 01024, Ukraine

\begin{abstract}
INTRODUCTION: Our previous studies have shown that exposure of acupuncture points (AP) or painful area of mice to halogen polarized light (PL) effectively weakens the pain. The aim of the study was to determine whether exposure of AP or painful area to LED red-infrared PL evokes analgesic effect. METHODS: The duration of licking the formalin-injected foot (tonic pain) was recorded in control group and mice exposed ( $5 \mathrm{~min}, 10 \mathrm{~min}$ ) to red+infrared LED light on AP E-36 or on the painful area. Power density of the light varied from 0.3 to $16.5 \mathrm{~mW} / \mathrm{cm}^{2}$. RESULTS: Exposure of AP E-36 or painful area to red-infrared LED PL evoked statistically significant decrease of licking time. The effect depended on the light application duration and its power density. 10-minute light exposition was more effective than 5-minute. The exposure of pain source to LED PL shortened the licking time to $44.1 \%$ (at 16.5 $\mathrm{mW} / \mathrm{cm}^{2}$ ) and to $64.4 \%$ (at $0.3 \mathrm{~mW} / \mathrm{cm}^{2}$ ). CONCLUSION: The results show the efficacy of pain suppression by exposure of antinociceptive AP or painful area to LED red+infrared PL. The effect depends on the duration of light exposure and its power density.
\end{abstract}

Key words: Red+infrared polarized LED light, acupuncture point, pain, formalin test.

\section{Introduction}

Previously performed experimental studies [1-9] demonstrated that polychromatic (white) and monochromatic (color) polarized light (PL) during the action on the locus of pain or acupuncture point (AP) evoked statistically significant analgesia. In these studies, the source of polychromatic light was halogen lamp installed in BIOPTRON devices (Zepter, Switzerland) [10, 11]. Polarization was achieved by reflecting the light from the glass package, located at the Brewster angle. The use of color filters allowed to obtain additional seven monochromatic ranges. We singled out the dependence of PL analgesia effects on the time of exposure and the light wavelength (color). Red and infrared light (R+IR) most powerfully suppressed pain, whereas cold colors of the spectrum anesthetized with less efficiency [9]. We also found out that the polarization of light intensified its biological (analgesic) effect [12].

Corresponding author: Sergiy Gulyar, M.D., Ph.D., professor, research fields: medicine, physiology.
The new generation of lighting devices uses LEDs as a light source. Their advantage is the autonomy and the ability to create light range required for each case. The most popular is the $\mathrm{R}+\mathrm{IR}$ range. In different devices (Medolight, Ecozept, Stomalight et al.), depending on the destination, there are combined multiple types of LEDs which are arranged with different density and configuration [13]. In the LED unit (ECOZEPT-PRO-LED) R+IR light beams are polarized. This is accomplished by using the method of polarization, the same as in Bioptron device. Since there is evidence of the analgesic effectiveness of the polarized R+IR halogen light, it is interesting to evaluate the presence of analgesic effect of polarized $\mathrm{R}+\mathrm{IR}$ diode light. Exploratory research turned out encouraging [14].

The aim of this study was to verify experimentally a possibility of pain relief by acting on the painful area, or the AP by polarized R+IR LED light. Furthermore, it is important for clinicians to determine the dependence of the analgesic effect of exposure to light and its power density, and to compare effects of polarized 
R+IR LED light and R+IR halogen light.

\section{Materials and Methods}

\subsection{Animals}

Today, the methods of quantitative evaluation of pain intensity in humans are absent because of the inherent emotional response to pain. Therefore, studies were performed on standardized animals (adult male albino mice weighing 27-33 g), contained in the vivarium and adapted to the conditions of the experiment. The use of similar experimental conditions allowed to quantify the intensity of pain before and after light applications and carry out a valid statistical comparison of results of different series. Each series consisted of 10-15 animals. All experiments were performed between 10:00 and 12:00 am. The mice were individually housed in plastic cages $(36 \times 24 \times 5$ $\mathrm{cm})$ and brought to the test room one day before testing for adaptation. Animals had free access to water and food. Each mouse was used in one experiment only. After the experiment the mice received a lethal dose of urethane (intraperitoneally). All the experiments were performed in accordance with the ethical guidelines recommended by the International Association for the Study of Pain for experimental pain in animals.

\subsection{Induction of Painful Area}

Tonic somatic pain was studied in formalin test model, which is well described in the literature and is widely used to determine the effectiveness of analgesic action of various substances or physical therapy factors [15-17]. The pain caused by subcutaneous injection (10 $\mu \mathrm{l} / 10 \mathrm{~g}$ weight) of $5 \%$ formalin solution (dissolved in $0.9 \% \mathrm{NaCl}$ solution) into the plantar surface of the left hind foot. As it is known, there occurs inflammatory focus in the injection site, which is the source of pain for a few hours, but especially in the first 60 minutes. The intensity of pain was evaluated by duration of the animal's feet licking cycles during each 10 min period after light application and for $60 \mathrm{~min}$ of observation. As it is known, pain response to formalin is composed of two phases: early phase - the acute pain (lasting no more than 10 minutes) and late phase-tonic pain (lasting more than one hour). As in our experiments immediately after injection of formalin solution there was made a 10 minute application of light, during which the animal was kept in a special chamber, partially limiting motor activity, we could not observe the first phase of the pain response. In the future, we are talking only about the second - tonic phase of pain. The non-painful behavioral reactions (sleeping, washing, running and eating) were recorded too.

\subsection{Applications of Polarized Lights}

Immediately after formalin injection the application of LED or Halogen PL on the painful area or AP E-36 was made (duration of exposure was 5 minutes or 10 minutes). During exposure to PL animals were kept in a narrow plastic chamber with hole for the left hind limb. For light applications we used devices ECOZEPT-PRO-LED and BIOPTRON-Compact.

ECOZEPT-PRO-LED device is a LED light source (R+IR LED light), converted into polarized stream with Stoletov's glass stack located on the flow of light at the Brewster angle. We used red (LXM2-PD01-0050) and infrared (HIR-C06 /L298/P01/TR) LED light with power of $540 \mathrm{~mW}$ and $350 \mathrm{~mW}$ with a wave range of $637 \mathrm{~nm}$ and $860 \mathrm{~nm}$, respectively.

BIOPTRON-Compact is a source of halogen light, equipped with a similar system of polarized light. This device produces linearly polarized, polychromatic, incoherent light with wavelengths from $480 \mathrm{~nm}$ to 3400 $\mathrm{nm}$. The power density of this device is $40 \mathrm{~mW} / \mathrm{cm}^{2}$. We used a red filter that transmits red and infrared light components ( $\mathrm{R}+\mathrm{IR}$ halogen light, 650-3900 nm). The distance from the filter device to the skin was $5 \mathrm{~cm}$. In order to reduce the light spot (due to the small size of the experimental animals), we used a light proof nozzle with a hole diameter of $5 \mathrm{~mm}$. As a control (placebo) served a series of experiments on animals with pain reaction without exposure to light, but all other conditions being equal. After the end of light 
application (experimental groups) or imitation of light application (control group), animals were returned to their cages to evaluate painful and non-painful behavior parameters during $60 \mathrm{~min}$.

\subsection{Statistic Analysis}

A special computer program calculated the duration of each behavioral response for each successive 10 minutes, and for the entire period of observation (60 min). Data were represented as means \pm SEM. Student's t-test was used to evaluate the statistical significance of the results. Differences were considered statistically significant at $P<0.05$.

\section{Results}

\subsection{Effects of LED and Halogen Polarized Light on} Formalin-Induced Pain

In the present study, we obtained objective evidences of analgesic action of polarized R/IR LED light. We found out that this light was the same effective, and sometimes exceeded polarized R+IR halogen light. This is clearly seen by comparing the duration of pain in different groups (Fig. 1, Table 1). Dynamics of pain response in the group receiving a session of the LED light, differed from a similar reaction in the group exposed to halogen light (Fig. 1). Evidently, that the most powerful weakening of pain under influence of $\mathrm{R}+\mathrm{IR}$ diode light took place in the first 30 minutes of observation. Peak pain, observed in the time interval of 20 minutes in the control group and in the group which received the session of $\mathrm{R}+\mathrm{IR}$ halogen light, was absent here.

In both groups, in which PL was applied the pain was statistically significant $(P<0.001)$ weaker than in the control group (without application of light). The minimum duration of pain response was observed in the group, which received R+IR LED light. Here, the pain lasted $249.5 \pm 55.8 \mathrm{~s}$ that was $44.1 \%$ of the control $(566.2 \pm 47.1$ s). Pain reduction was even more pronounced than from the application of R+IR halogen light (307.4 $\pm 49.3 \mathrm{~s}$ or $54.3 \%$ of the control). When comparing the non-painful reactions in the three groups,

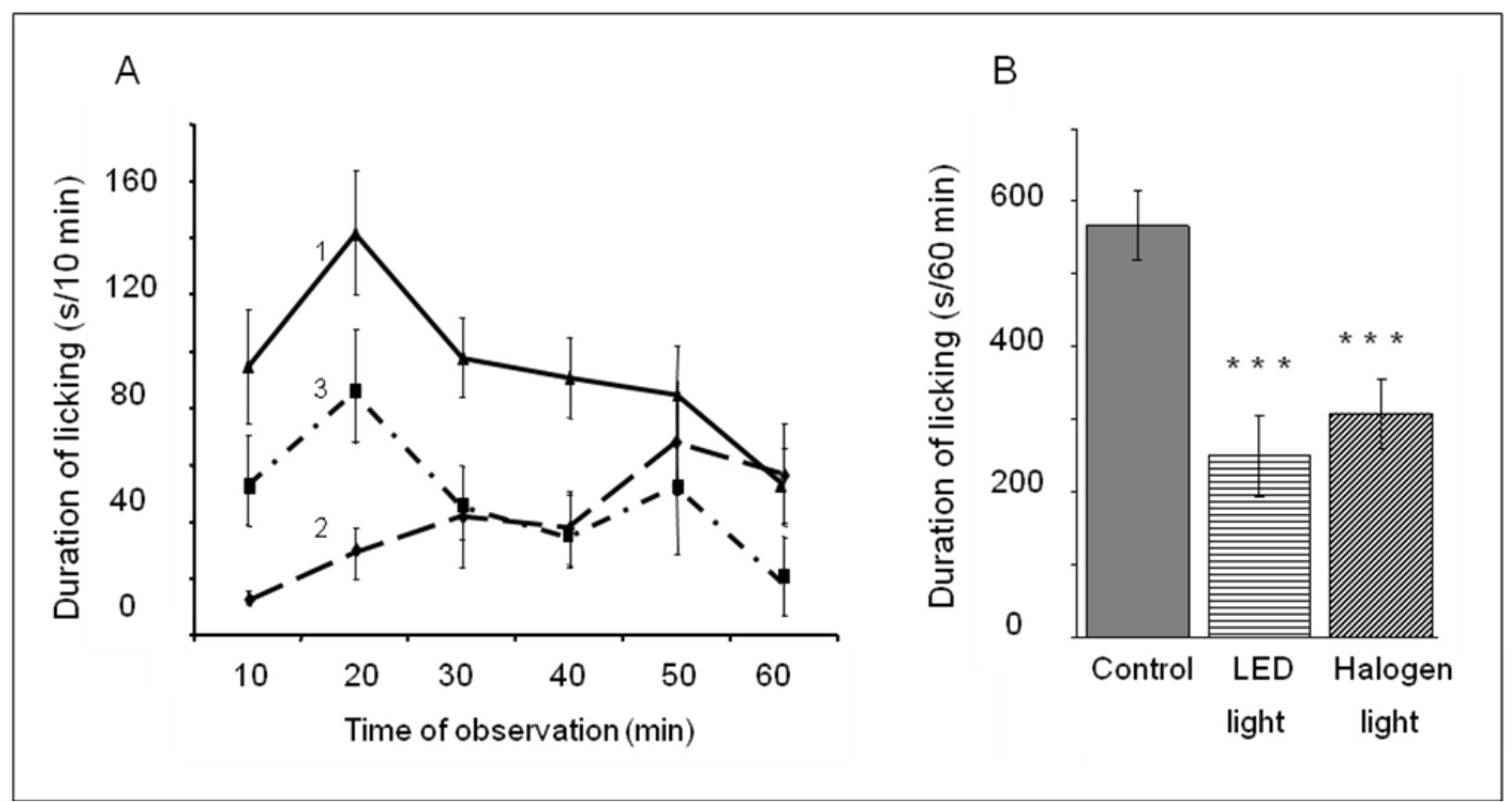

Fig. 1 The effects of polarized LED light and Halogen light on formalin-induced pain behavior in mice. (A) Dynamics of pain behavioral reaction (licking of the affected paw) caused by formalin. Duration of licking was measured during each 10 min period after light application. 1- the control group; 2- the group treated with LED light; 3- the group treated with halogen light. (B) Cumulative data for 60 min of observation. Bars represent mean \pm S.E.M.

${ }^{* * *} P<0.001$, significance of a difference from the control group data (without light application). 
Table 1 Duration ( $\mathrm{s} / 60 \mathrm{~min}$ of observation and \% from the control group) of pain and non-painful behavioral responses in the control group (without light application) and two experimental groups, in which we applied polarized R+IR LED light or R+IR halogen light. Exposure of light-10 minutes distance from the filter $5 \mathrm{~cm}$.

\begin{tabular}{llll}
\hline Behavioral responses & Control (placebo) & LED light & Halogen light \\
\hline \multirow{2}{*}{ Licking } & $566.2 \pm 47.1$ & $249.5 \pm 55.8 * * *$ & $307.4 \pm 49.3 * * *$ \\
& $100 \%$ & $44.1 \%$ & $54.3 \%$ \\
Sleeping & $386.3 \pm 79.3$ & $377.6 \pm 173.2$ & $592.4 \pm 152.2 *$ \\
& $100 \%$ & $97.8 \%$ & $153.4 \%$ \\
Washing & $137.9 \pm 32.5$ & $154.4 \pm 35.5$ & $176.4 \pm 43.1 *$ \\
& $100 \%$ & $111.9 \%$ & $127.9 \%$ \\
Running & $65.5 \pm 13$ & $256.1 \pm 103.3$ & $135.9 \pm 60.7 *$ \\
Eating & $100 \%$ & $391.2 \%$ & $207.9 \%$ \\
\hline
\end{tabular}

Significance of differences with the control group: $* P<0.5$; *** $P<0.001$ (the rest is not significant).

it was found that R+IR LED light causes a smaller change in duration of non-painful reactions (sleeping, washing, running and eating) than the R/IR halogen light. In the group, which received R+IR halogen light, the duration of non-painful behavior increased statistically significantly.

Thus, the experimentally established fact of weakening somatic pain after application of polarized R+IR LED light. Pain reduction was even more pronounced than at application of $\mathrm{R}+\mathrm{IR}$ halogen light. Analgesia was $55.9 \%$ and $45.7 \%$, respectively. Peculiarity of the R+IR LED light action was the lack of maximum pain, usually observed at 20th minute, which meant a more intensive initial analgesia.

\subsection{Dependence of LED Light Effects on the Power Density}

We discovered the dependence of analgesic effect of LED light from its power (Fig. 2). At its power density of $16.5 \mathrm{~mW} / \mathrm{cm}^{2}$, the pain was minimal, it amounted $44.1 \%$ of the control. Reduction of the luminous flux intensity led to the analgesic effect weakening. Pain made up $61.4 \% \quad\left(1.0 \mathrm{~mW} / \mathrm{cm}^{2}\right)$ and $64.4 \% \quad(0.3$ $\mathrm{mW} / \mathrm{cm}^{2}$ ) of the control.

Totals of pain reactions in different groups are given in Table 2. In all the three groups, in which polarized R+IR LED light was applied, pain was significantly less than in the group without light application (placebo).

Duration of all non-painful reactions in the groups in which PL was applied, increased. In contrast to placebo, after a session of light therapy, animals significantly longer did washing, running, eating or sleeping, it also testifies to pain relief.

\subsection{Dependence of LED Light Analgesic Effect on the Exposure Duration}

We also studied dependence of the effect of the exposure of LED light duration on the painful area. Behavioral reactions (licking of the staggered paw) to the pain induced by formalin injection, before and after LED light exposure for 5 or 10 min duration are shown in Fig. 3. The analysis of pain reactions in the three groups showed distinctly, that in both experimental groups pain was weaker, than in the control. Thus 5-minute exposure to light was less effective in comparison to 10-minute.

Fig. 3 and Table 3 show that in both groups, in which polarized LED light was applied, pain responses were significantly different in comparison with the control animals (placebo). A total pain reaction during 60 minutes of observation in a placebo-group was $566.2 \pm$ $47.1 \mathrm{~s}$, after 10 minute of R+IR LED light application it was $347.6 \pm 38.1 \mathrm{~s}$, and after 5 minute session-443.9 $\pm 69.2 \mathrm{~s}$.

If duration of pain reaction in the placebo-group to accept as $100 \%$, after the LED light application pain was $78.4 \%$ (5 minutes) and $61.4 \%$ (10 minutes) of the control. Distinction between two experimental groups is statistically reliable. At $10 \mathrm{~min}$ exposition, there was 


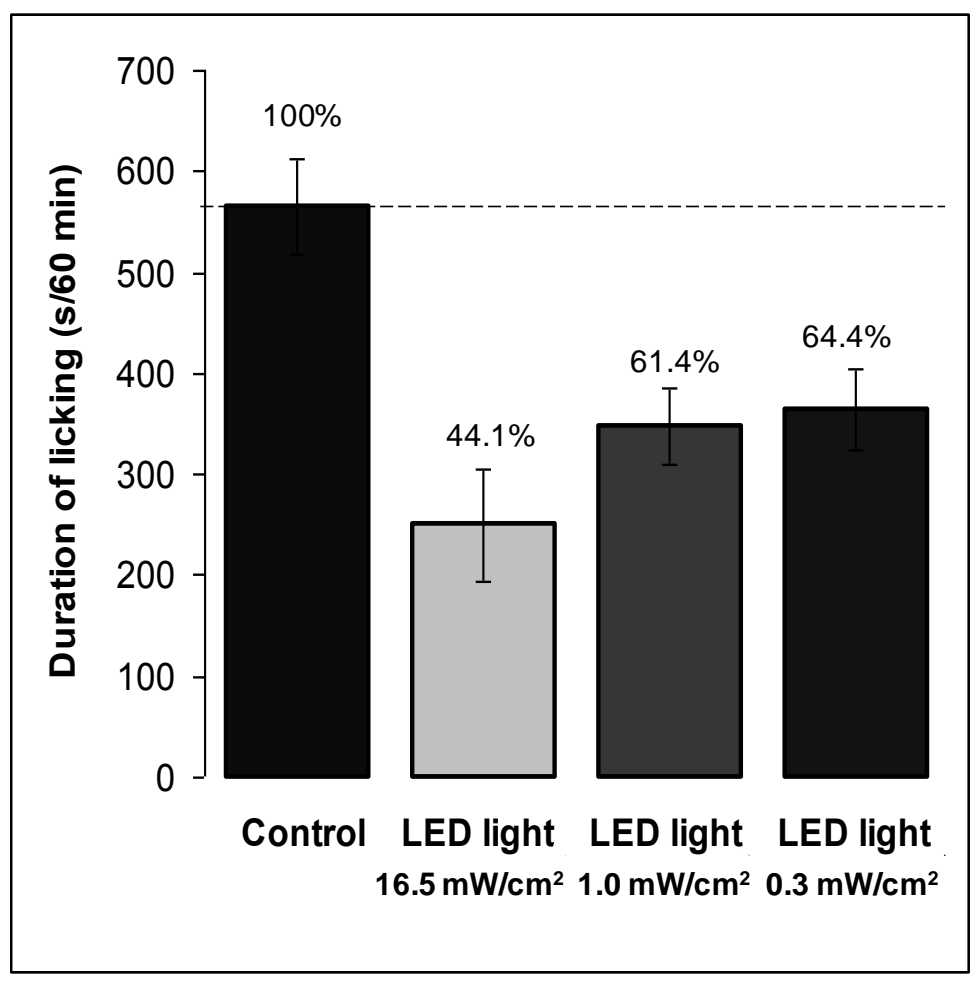

Fig. 2 Comparison of pain response duration (licking the affected paw) for 60 minutes in the control group (without application of light) with the three experimental groups in which 10 minute application on the locus of pain by R+IR LED light of different power was performed. Numbers above the bars-the duration of pain in $\%$ of the control group taken as $100 \%$. Bars represent mean \pm S.E.M.

Table 2 The duration of pain reactions in the control group (without light application) and in the three experimental groups with application of LED light.

\begin{tabular}{|c|c|c|c|}
\hline \multirow{2}{*}{$\begin{array}{l}\text { Control } \\
\text { group }\end{array}$} & \multicolumn{3}{|c|}{$\begin{array}{l}\text { After } 10 \text { minutes of exposure to the locus of pain } \\
\text { R+IR LED light of different power }\end{array}$} \\
\hline & $16.5 \mathrm{~mW} / \mathrm{cm}^{2}$ & $1.0 \mathrm{~mW} / \mathrm{cm}^{2}$ & $0.3 \mathrm{~mW} / \mathrm{cm}^{2}$ \\
\hline $\begin{array}{l}566.2 \pm 47.1 \mathrm{~s} \\
100 \%\end{array}$ & $\begin{array}{l}249.5 \pm 55.8 \mathrm{~s}^{* * *} \\
44.1 \%\end{array}$ & $\begin{array}{l}347.6 \pm 38.1 \mathrm{~s} * * * \\
61.4 \%\end{array}$ & $\begin{array}{l}364.6 \pm 40.5 \mathrm{~s}^{* *} \\
64.4 \%\end{array}$ \\
\hline
\end{tabular}

** $P<0.1$; *** $P<0.002$, compared with the control value.

significant increase of time of all unpainful reactions (slipping, washing, running, eating). In the group, in which the session of light application lasted for 5 minutes, only slipping and running were more than in the control, and two other behavioral reactions (washing, eating) did not significantly differ from the control.

\subsection{Analgesic Effect Can Be Obtained by Application} of LED Light Not Only on the Focus of Pain, But Also on the Acupuncture Point

Our experiments have shown that the pain relief can be obtained by applications of polarized R+IR LED light not only on the locus of pain, but also on the AP. The AP E-36 used in our experiments, is one of the most frequently used AP to suppress pain. Fig. 4 shows the pain reactions for one hour of observations in animals treated with $10 \mathrm{~min}$ exposure to polarized R+IR LED light on AP-36 and on the locus of pain. You can see that in both experimental groups, in which the R+IR LED light was applied pain was weaker in comparison to control animals that received phototherapy simulation session.

Total pain reaction during 60 minutes of observation (Fig. 4 and Table 4) without light application was 476.5 


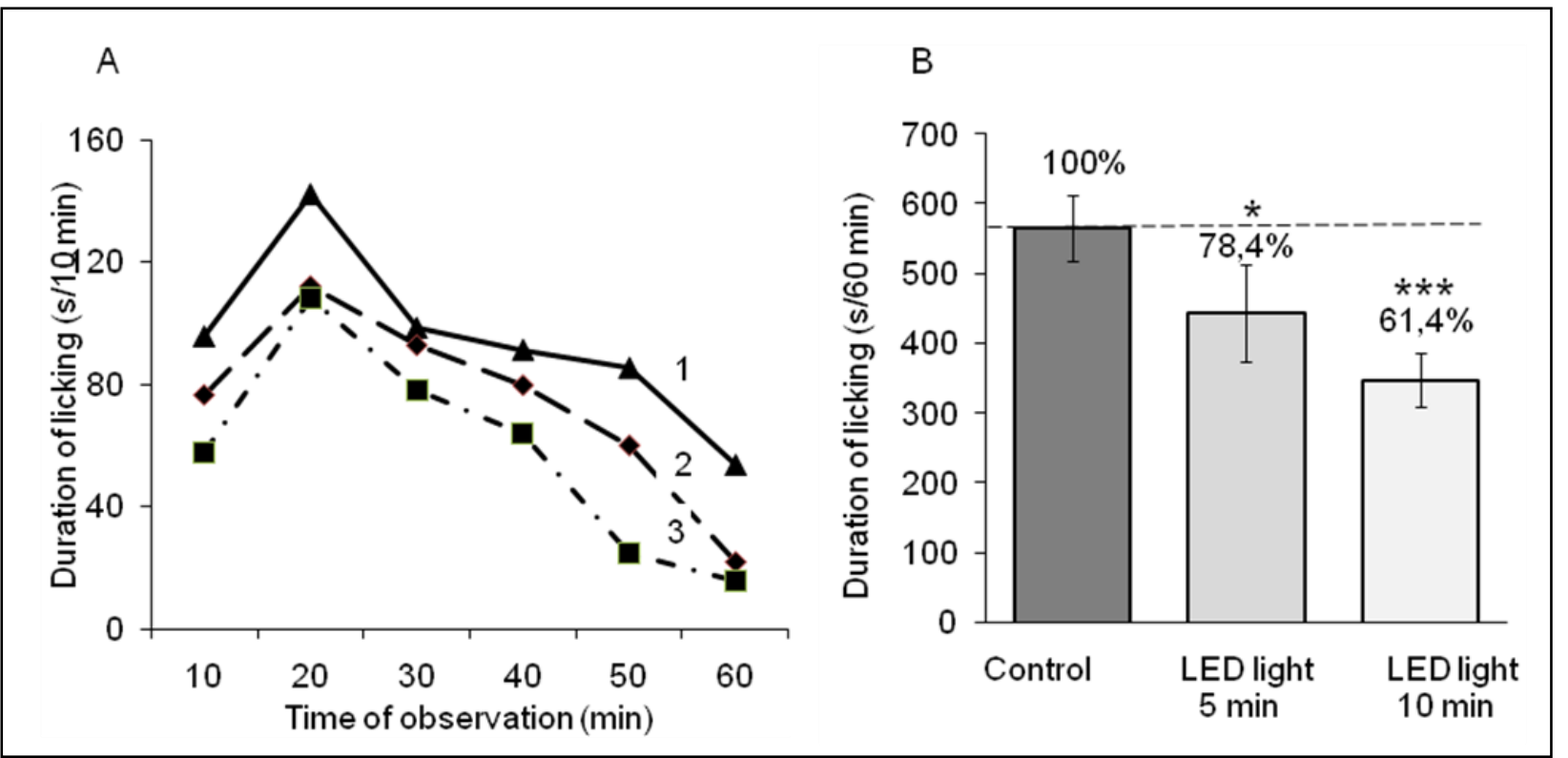

Fig. 3 Dependence of the formalin-induced pain behavioral response (licking of the staggered paw) on exposure of painful area to polarized LED light. (A) Dynamics of pain behavioral reaction caused by formalin in the control group (1) and the groups treated with LED light during $5 \mathrm{~min}$ (2) or $10 \mathrm{~min}$ (3). Duration of licking was measured during each $10 \mathrm{~min}$ period after light application. (B) Cumulative data for 60 min of observation. Bars represent mean \pm S.E.M. Numbers above the bars the duration of pain in $\%$ of the control group taken as $100 \%$.

${ }^{* * * *} P<0.002,{ }^{*} P<0.002$, significance of the difference with the effect in the control group (without light application).

Table 3 Duration (s/60 min of observation and \% of the control group) of pain and non-painful behavioral responses in the control group (without application of light) and two experimental groups, in which R+IR LED polarized light was applied during 5 or 10 min.

\begin{tabular}{llll}
\hline Behavioral responses & Control (placebo) & $\begin{array}{l}\text { LED light } \\
10 \mathrm{~min}\end{array}$ & $\begin{array}{l}\text { LED light } \\
5 \mathrm{~min}\end{array}$ \\
\hline \multirow{2}{*}{ Licking } & $566.2 \pm 47.1$ & $347.6 \pm 38.1 * * *$ & $443.9 \pm 69.2^{*}$ \\
& $100 \%$ & $61.4 \%$ & $78.4 \%$ \\
Sleeping & $386.3 \pm 79.3$ & $721.1 \pm 143.7^{*}$ & $598 \pm 160.7^{*}$ \\
Washing & $100 \%$ & $186.7 \%$ & $154.8 \%$ \\
& $137.9 \pm 32.5$ & $213.7 \pm 37.2 *$ & $156 \pm 38.4$ \\
Running & $100 \%$ & $154.9 \%$ & $113.1 \%$ \\
Eating & $65.5 \pm 13$ & $103.4 \pm 32.1 *$ & $90.4 \pm 30.7^{*}$ \\
\hline
\end{tabular}

$* P<0.5 ; * * * P<0.002$, significance of the difference of the effect in the control group (others are not significant).

$\mathrm{s}$ and after exposure of the locus of pain or AP E-36 to the LED light it was $364.6 \mathrm{~s}$ and $369.1 \mathrm{~s}$ respectively. In both experimental groups, pain was significantly less $(P<0.01)$, than in the group without light application. At the same time, the difference between the two experimental groups was not significant.

Analysis of non-painful behavioral reactions (sleeping, running, washing, eating) showed that in the group that received R/IR LED light on AP E-36, these reactions did not differ significantly from those in the control group. After exposure to light of the center of pain to light, non-painful reaction, although different from the controls, but the significance of a difference was not high (Table 4).

\subsection{Polarized LED Light Does Not Affect the Behavior of Animals in Case of Pain Absence}

To further verify the reliability of the analgesic action of the R/IR LED light, it was necessary to check whether it, by itself does not affect the behavior of 


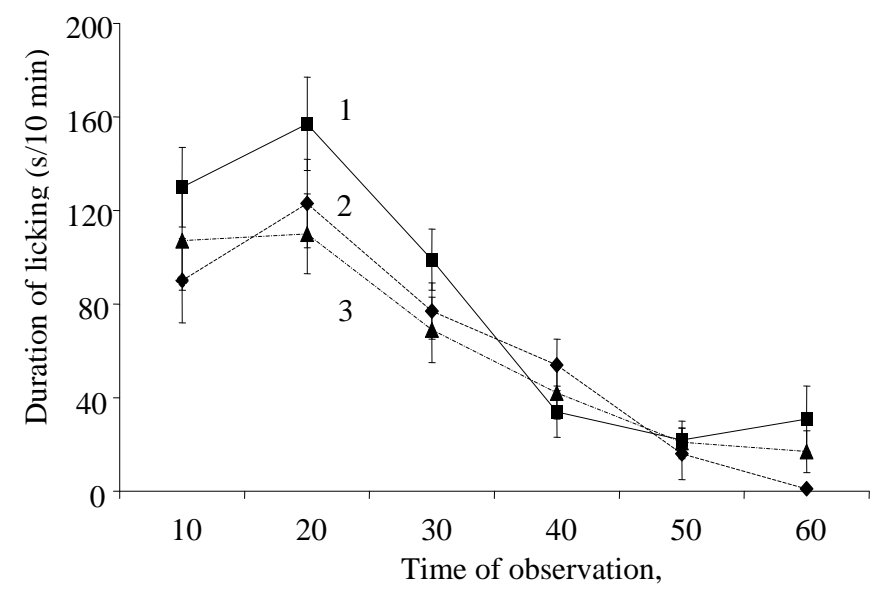

B

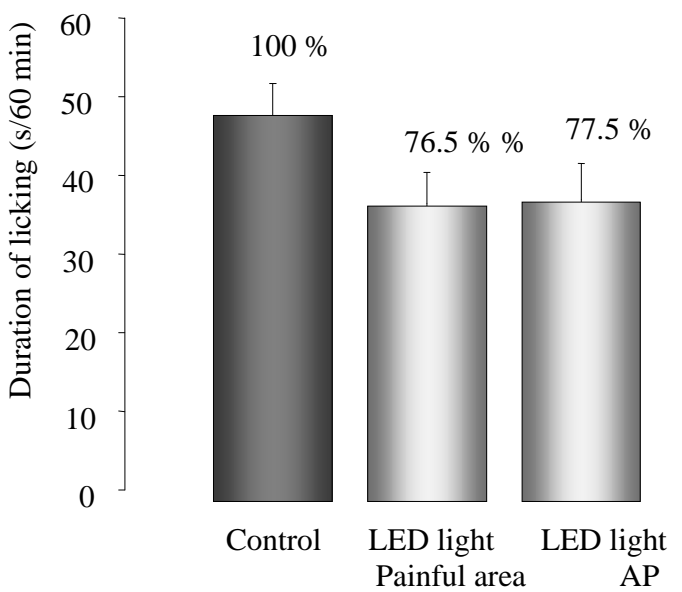

Fig. 4 Comparison of R/IR LED light effects during its application on the pain locus and on the analgesic acupuncture point E-36. (A) Dynamics of the pain reactions without light (1) and after 10 minutes of light applications on the pain center (2) or on acupuncture point E-36 (3). (B) Duration of pain responses in two experimental and one control group for 60 minutes of observation. Bars represent mean \pm S.E.M. Numbers above the bars-duration of pain in $\%$ of the control group taken as $100 \%$.

Table 4 Duration ( $\mathrm{s} / 60 \mathrm{~min}$ of observation and \% of the control group) of painful and non-painful behavioral responses in the control group (without application of light) and two experimental groups, where polarized R+IR LED light was applied on the painful area or on AP E-36.

\begin{tabular}{llll}
\hline Behavioral responses & Control (placebo) & $\begin{array}{l}\text { LED light } \\
\text { Painful area }\end{array}$ & $\begin{array}{l}\text { LED light } \\
\text { AP E-36 }\end{array}$ \\
\hline \multirow{2}{*}{ Licking } & $476.5 \pm 41.2 \mathrm{c}$ & $364.6 \pm 40.5 \mathrm{c} * * *$ & $369.1 \pm 46.5 \mathrm{c}^{* * *}$ \\
& $100 \%$ & $76.5 \%$ & $77.5 \%$ \\
Sleeping & $854.4 \pm 170.6 \mathrm{c}$ & $701.1 \pm 124.5 \mathrm{c} *$ & $854.4 \pm 170.6 \mathrm{c}$ \\
& $100 \%$ & $82.1 \%$ & $105.9 \%$ \\
Washing & $112.4 \pm 31.5 \mathrm{c}$ & $12748.5 \pm 35.7 \mathrm{c}^{* * *}$ & $127.4 \pm 30.8 \mathrm{c}$ \\
& $100 \%$ & $180.5 \%$ & $113.4 \%$ \\
Running & $67.9 \pm 13.5 \mathrm{c}$ & $133.4 \pm 48.1 \mathrm{c}^{*}$ & $58.9 \pm 15.2 \mathrm{c}$ \\
Eating & $100 \%$ & $196.6 \%$ & $86.8 \%$ \\
\hline
\end{tabular}

* $P<0.5 ; * * * P<0.01$, significant difference with the control group (others not significant).

animals. For this purpose, we performed a two series of experiments on the animals without painful stimuli. Instead of the formalin solution injection the animals were administered $0.9 \% \mathrm{NaCl}$ solution (subcutaneous injection in foot dorsum of the left hind limb). In the first series, we studied the behavioral responses of animals in normal conditions (without painful stimuli and without LED light application). In the second series after injection of $\mathrm{NaCl}$ solution, animals received
10 minute exposure of R+IR LED light on the foot (the area where the pain locus was usually created). The duration of the left foot hind licking in both groups was similar (32 $\pm 12 \mathrm{~s}$ and $25 \pm 4 \mathrm{~s}$ ). In the group, in which polarized LED light was used, the behavior of animals not in any of the five registered parameters (limb licking, running, washing, sleeping, eating) did not differ significantly from the behavior of animals in norm (without R+IR LED light application). Significant 


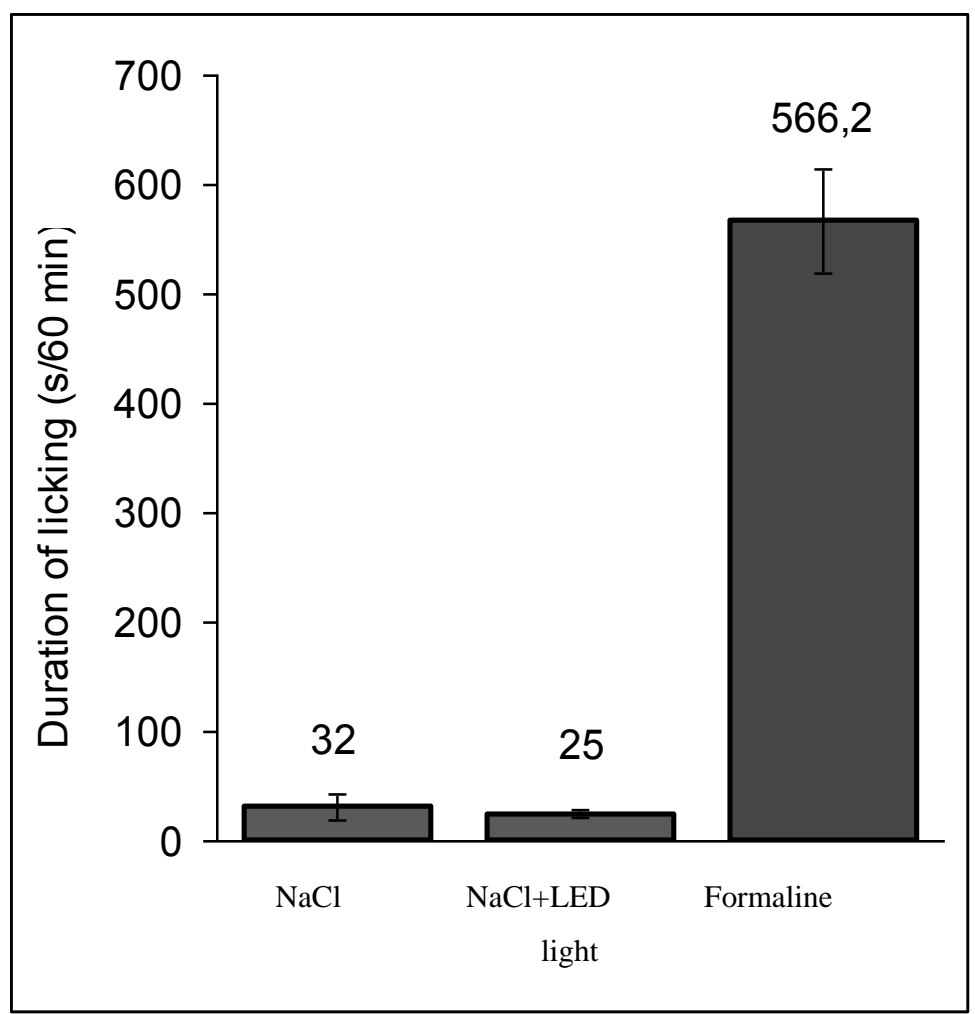

Fig. 5 Comparison of total ( $60 \mathrm{~min}$ of observation) duration of licking of the left hind limb by the animals of the three groups: 1 - without a pain stimulus and light $(\mathrm{NaCl}) ; 2$ - without a pain stimulus, but after 10 minute of affecting paw by R/IR polarized LED light (NaCl+LED light); 3 - for animals with the pain locus (Formaline) without application of LED light.

pain reaction took place only after creation of the pain sours in the foot (the injection of $5 \%$ formalin solution). The duration of licking increased up to $566.2 \pm 47 \mathrm{~s}$ (Fig. 5).

It follows that the polarized R/IR LED light (power density $16.5 \mathrm{~mW} / \mathrm{cm}^{2}, 10 \mathrm{~min}$ of exposure) by itself did not change the behavioral responses of animals. Thus, observed in our experiments, the effects of R+IR LED light on formalin-induced response is specifically analgesic.

\section{Discussion}

Main findings of this study are: (1) $R+I R$ polarized LED light significantly reduces somatic pain. (2) This effect has a dose-dependent character. (3) Analgesia can be evoked by light application on the locus of pain or on AP E-36.

Previous studies performed at the Bogomolets Institute of Physiology of NAS of Ukraine, revealed weakening of the somatic pain response under the action of nonpolarized R+IR LED light [13] and polarized halogen light [1-9]. The results of the above experiments objectively prove the analgesic effect of polarized R+IR LED light.

This fact was obtained on the model of formalin pain test. We proved that polarized R/IR LED light with wavelengths $637 \mathrm{~nm}$ and $860 \mathrm{~nm}$ at application on the pain locus or on AP E-36, really has analgesic effect. The presence of this effect was empirically assumed, as there were clinical observations proving this fact. However, the experimental evidence was missing, and only the above data corrected the lack of evidence.

Low-level laser therapy has been widely applied for pain relief in some clinical situations. However, the influence of LED therapy on pain syndromes has been weakly investigated. Recently the significant reduction of pain was discovered during both the red and the infrared LED irradiation $(630 \mathrm{~nm}$ and $850 \mathrm{~nm}$ ) 
of patients with temporomandibular disorders [18]. Authors conclude that LED devices constitute an attractive alternative for low-level laser therapy. Our experimental data with somatic pain (formalin test) provide objective evidence of the $\mathrm{R}+\mathrm{IR}$ polarized diode light analgesic action.

As our experimental model allows to evaluate the intensity of pain in numbers, we were able to compare the effects of R+IR polarized LED light depending on its capacity and duration of exposure. For the first time we compared the analgesic actions of the $\mathrm{R}+\mathrm{IR}$ diode and $\mathrm{R}+\mathrm{IR}$ halogen light.

We singled out dependence of the analgesic effect of polarized R+IR LED light on the time of application and power of radiation. 10-minute light exposure was more effective than 5-minute. At power density of the light $16.5 \mathrm{~mW} / \mathrm{cm}^{2}$, the pain was minimal; it was $44.1 \%$ of the control. By reducing the light intensity to $0.3 \mathrm{~mW} / \mathrm{cm}^{2}$ of the pain response lowering was less pronounced. Pain made up $64.4 \%$ of the control. Analgesia was $55.9 \%$ and $35.6 \%$, respectively. This means that not every bright light source can cause a biological effect, which could be used with a clinical purpose. We discovered that at the same polarization, the effect of the R/IR diode light equipped with the most efficient red filter is not inferior and sometimes superior to the halogen light. At equal exposure, analgesia was $45.7 \%$ and $55.9 \%$, respectively. Characteristic of a diode light was the absence of pain maximum, usually observed at 20th minute, which means a more intense initial analgesia.

Our results about analgesic action of $\mathrm{R}+\mathrm{IR}$ LED light are consistent with a few studies of other authors. It has been shown [19] that rats with pain caused by injection of capsaicin into the plantar region of the foot (same area as in our experiments), after lighting the source of pain by R+IR LED light $(627 \mathrm{~nm})$ there increased the pain threshold to mechanical stimulus, that testified to the decrease of pain sensitivity.

In experiments on mice, it was shown that $\mathrm{R}+\mathrm{IR}$ LED light (luminous rug, light application from the below on the whole animal) suppresses acute and formalin-induced pain [20]. We found out that application of non polarized red and infrared diode light on the painful area or on AP E-36, decreased the intensity of pain reactions [13]. When testing different frequencies of light interruptions $(10,600,8000 \mathrm{~Hz})$ the most effective for the tonic pain suppression were frequency of $10 \mathrm{~Hz}$ and $8000 \mathrm{~Hz}$ [13].

We have shown that the analgesic effect can be obtained by application of PL not only on the pain source, but on the analgesic AP. Analgesia occurred at AP exposition to PL of the diode [14] and halogen nature [1-9]. In this case, we confirmed the previously obtained new evidence of PL influence on AP. It is known that all animals have APs and connecting them extra ocular and unnerve transmission ways of electromagnetic signals (Meridians) [21]. They, on the topography and structural-functional properties, coincide with the analogous system in humans [22]. This allows us to use the results of influence on APs, obtained in experiments with animals for understanding therapeutic effects of acupuncture in humans [23-25].

The data on mechanisms of R+IR LED light analgesic action are practically absent. The biological mechanisms involved in the effects of diode light influence are described in literature as similar to laser. $\mathrm{R}+\mathrm{IR}$ LED light is similar to laser, but it is not coherent. As for low intensity laser light therapy, it is believed that it is based on synthesis increase and release of endorphins, and also decrease of bradykinin and serotonin release [26, 27]. Data from the literature demonstrate that laser acupuncture on ST-36 inhibits acid-induced abdominal constrictions and both phases (neurogenic and inflammatory) of formalin-induced nociceptive behavior of rats [28]. Authors consider that significant antinociceptive effect of laser acupuncture is mediated by activation of opioidergic and serotonergic (5-HT1 and 5-HT2A receptors) systems.

Another mechanism of the pain weakening can be reduction of the conduction velocity in sensory nerves 
[29-33]. There are evidences that laser irradiation applied to undamaged skin may produce a direct, local effect on conduction in underlying nerves. Investigations of the effects of low intensity laser irradiation $(830 \mathrm{~nm})$ on the conduction delay in the human median nerve have shown small but significant increase of latencies [34].

The laser light (especially red) expands micro vessels, increases the blood flow, accompanied by better oxygenation, increases lymphatic drainage and metabolism in the affected tissues, which also contributes to alleviation of pain [29, 35-38].

It can be assumed that application of R+IR LED light on AP launches its own analgesic systems in the brain, as it was shown in case with classical acupuncture. It is known that stimulation of AP E-36 and some other APs produces a simultaneous release of enkephalin, beta-endorphin, endomorphin and dynorphin, the peptides that play an essential role in mediating analgesic effect of acupuncture [39].

\section{Conclusion}

Thus, we can conclude that the polarized R+IR LED light significantly reduces formalin-induced pain response. The effect can be obtained by application of light on the source of pain and AP. The degree of analgesia depends on the power density of light flux and duration of application. It was discovered that polarized R+IR LED light performance is not inferior and sometimes superior to red halogen light. With equal exposure, analgesia was $45.7 \%$ and $55.9 \%$, respectively. On this basis, we can assume that $R+I R$ LED polarized light will alleviate pain at different pain syndromes in humans.

\section{References}

[1] Gulyar, S., Limansky, Y., and Tamarova, Z. 1999. “Analgesic Effects of Bioptron PILER Light." J. Practical Doctor (4): 21-3. (in Russian)

[2] Limansky, Y., Tamarova, Z., Bidrov, E., and Kolbun, N. 1999. "Suppression of Nociceptive Responses in Mice by Low-Intensity Microwave Exposure on Acupuncture Points.” Neurophysiology 31 (4): 290-4. (in Russian)
[3] Limansky, Y., Tamarova, Z., Gulyar, S., and Bidrov, E. 2000. "Study of Analgesic Effect of Polarized Light on Acupuncture Points." Fiziol. J. 46 (6): 105-11. (in Ukrainian)

[4] Limansky, Y., Tamarova, Z., and Gulyar, S. 2003. "Suppression of Visceral Pain by Action of the Low Intensity Polarized Light on Antinociceptive Points of Acupuncture.” Fiziol. J. 49 (5): 43-51.

[5] Limansky, Y., Tamarova, Z., and Gulyar, S. 2006. "Suppression of Pain by Exposure of Acupuncture Points to Polarized Light." Pain Res. Manag. 11 (1): 49-57.

[6] Gulyar, S., Limansky, Y., and Tamarova, Z. 2006. "Suppression of Pain by Influence of Bioptron-Polarized Light on Acupoints." Eropean J. Pain (10): S212.

[7] Limansky, Y., Tamarova, Z., and Gulyar, S. 2008. "Suppression of Visceral Pain by Exposure of Acupuncture Points to Low-Intensive Polarized Light." Abstracts of the 12th World Congress on Pain. August 17-22. Glasgow, Scotland, UK.- Pres. PT 338.

[8] Tamarova, Z., Limansky, Y., and Gulyar, S. 2009. "Antinociceptive Effects of Color Polarized Light in Animal with Formalin Test." Fiziol. J. (3): 81-93.

[9] Limansky, Y., Gulyar, S., and Tamarova, Z. 2009. "BIOPTRON-Analgesia: 12. Role of Color in Tonic Pain Suppression." In Anthology of Light Therapy. Medical BIOPTRON Technologies. Kyiv: Bogomoletz Institute of Physiology at the National Academy of Sciences of Ukraine, 722-31. (in Russian)

[10] Kehrli, J., and Urlich, A. 1988. "Therapeutic Lamp Emitted Polarized Light (BIOPTRON)." Patent (USA) 5,001, 608.- 8P.

[11] Kehrli, J., and Ulrich, A. 1989. "Patent (European) EP 0 311125 B1." European Patent Office (BIOPTRON).- P9.

[12] Limansky, Y., Gulyar, S., and Tamarova, Z. 2009. "BIOPTRON-Analgesia: 2. Comparative Estimation of Antinoticeptive Action of Polarized and Unpolarized Light." In Anthology of Light Therapy. Medical BIOPTRON Technologies. Kyiv: Bogomoletz Institute of Physiology at the National Academy of Sciences of Ukraine, 190-203. (in Russian)

[13] Sushko, B., Lymansky, Yu., and Gulyar, S. 2007. "Action of the Red and Infrared Electromagnetic Waves of Light-Emitting Diodes on the Behavioral Manifestation of Somatic Pain.” Fiziol. J. 53 (3): 51-60. (in Ukrainian)

[14] Gulyar, S., and Tamarova, Z. 2015. "Antipain Effect of the Red-Infrared Polarized Led Irradiation Ecozept Device." Proc. XLIII Intern. Sci-Pract. Conf.: Application of Lasers in Medicine and Biology. Kharkiv, 86-9. (in Russian)

[15] Dubuisson, D., and Dennis, S. 1977. "The Formalin Test: A Quantitative Study of the Analgesic Effects of Morphine, Nepedioine and Brain Stem Stimulation in Rats and Cats." Pain 4 (2): 161-74. 
[16] Hunskaar, S., and Hole, K. 1987. "The Formalin Test in Mice: Dissociation between Inflammatory and non-Inflammatory." Pain 30 (1): 103-4.

[17] Sugomoto, M., Kupaishi, Y., Satoh, M., and Takagi, H. 1986. "Involvement of Medullary Opioidpeptidergic and Spinal Noraderenergic Systems in the Regulation of Formalin-Induced Persistent Pain." Neuropharmacology 25 (5): 481-5.

[18] Panhoca, V., Lizapelli, R., Nunez, S., Pizzo, R., Grecco, C., Paolillo, F., and Bagnato, V. 2015. "Comparative Clinical Study of Light Analgesic Effect on Temporomandibular Disorder (TMD) Using Red and Infrared Led Thepapy.” Lasers Med. Sci. 30 (2): 815-22.

[19] Pozza, D., Fregapani, P., Blessmann Weber, J., De Oliveira, M., De Oliveira M., Neto N., and De Macedo Sobrinho, J. 2008. "Analgesic Action of Laser Therapy (LLLT) in an Animal Model." Med. Oral Patol. Oral Cir. Bucal. 13 (10): E648-652.

[20] Pigatto, G., Coelho, I., Aquino, R., Bauermann, L., and Santos, Ars. 2016. "Light-Emitting Diode Phototherapy Reduces Nocifensive Behaviour Induced by Thermal and Chemical Noxious Stimuli in Mice: Evidence for the Involvement of Capsaicin-Sensitive Central Afferent Fibers." Mol. Neurobiol. 2016 (Apr 7): 1-14.

[21] Gulyar, S., and Limansky, Y. 2003. "Mechanisms of Primary Reception of Electromagnetic Waves of Optical Range." Fiziol. J. 49 (2): 35-44.

[22] Schoen, A., Ed. 2001. "Veterinary Acupuncture." In Ancient Art to Modern Medicine. 2. St.Louis: Mosby. 9: 82-7.

[23] Shankar, N., Varshney, A., Bhattacharya, A., and Sharma, K. 1996. "Electroacupuncture, Morphine and Clonidine: A Comparative Study of Analgesic Effects." Indian J. Physiol. Pharmacol. 40 (3): 225-30.

[24] Cao, Q., Liu, J., Chen, S., and Han, Z. 1988. "Effects of Electroacupuncture at Neiguan on Myocardial Microcirculation in Rabbits with Acute Myocardial Ischemia." J. Tradit. Cnin. Med. 18 (2): 134-9.

[25] Luvsan, G. 1991. Traditional and Modern Aspects of Oriental Reflexotherapy. Moscow: Medicine, 20-310.

[26] Gur, A., Karakoc, M., Cevik, R., Nas, K., and Karakoc, M. 2003. "Efficacy of Low Power Laser Therapy and Exercise on Pain and Functions in Chronic Low Back Pain." Laser Surg. Med. 32 (3): 233-8.

[27] Walker, J. 1983. "Relief from Chronic Pain by Low Power Laser Irradiation.” Neurosci. Lett. 43 (2-3): 339-44.

[28] Erthal, V., Silva, M., Francisko, J., Cidral-Filho, E., and Nohama, P. 2013. "ST36 Laser Acupuncture Reduces Pain-Related Behavior in Rats: Involvement of the Opioidergic and Serotonergic Systems." Laser Med. Sci.
28 (5): 1345-51.

[29] Maegawa, Y., Itoh, T., Hosokawa, T., Yaegashi, K., and Nishi, M. 2007. "Effects of Near-Infrared Low-Level Laser Irradiation on Microcirculation." Lasers Surg. Med. 27 (5): 427-37.

[30] Ebert, D., and Roberts, C. 1997. "In vitro Frog Sciatic Nerve as a Peripheral Nerve Model for Studies of the Mechanisms of Action of Low Energy Lasers. Part One." Lasers Surg. Med. 21 (1): 32-41.

[31] Snyder-Mackler, L., and Bork, C. 1988. "Effect of Helium-neon Laser Irradiation of Peripheral Sensory Nerve Latency." Phys. Ther. 88 (2): 223-5.

[32] Cambier, D., Blom, K., Witvrouw, E., and Ollevier, G. 2000. "The Influence of Low Internsity Infrared Irradiation on Conduction Characteristics of Peripheral Nerve: A Randomized, Controlled, Double Blind Study on the Sural Nerve." Lasers Med. Sci. 15 (3): 195-200.

[33] Greco, M., Vacca, R., Moro, L., Perlino, E., Petragallo, V., Marra, E., and Passarella, S. 2001. "Helium-neon Laser Irradiation of Hepatocytes Can Trigger Increase of the Mitochondrial Membrane Potential and Cab Stimulation C-Fos Expression in a Ca2+-Dependent Manner." Lasers Surg. Med. 29 (5): 433-41.

[34] Baxter, G., Walsh, D., Allen, J., Lowe, A., and Bell, A. 1994. "Effects of Low Intensity Infrared Laser Irradiation upon Conduction in the Human Median Nerve in vivo." Exper. Physiol. 79 (2): 227-34.

[35] Hakguder, A., Birtane, M., Gurcan, S., Kokino, S., and Turan, F. 2003. "Efficacy of Low Level Laser Therapy in Myofascial Pain Syndrome: An Algometric and Thermographic Evaluation.” Lasers Surg. Med. 33 (5): 339-43.

[36] Gur, A., Sarac, A., Cevik, R., Altindag, O., and Sapac, S. 2004. "Efficacy of 904 NM Gallium Arsenide Low Level Laser Therapy in the Management of Chronic Myofascial Pain in the Neck: A Double-Blind and Randomize-Controlled Trial." Lasers Surg. Med. 35 (3): 229-35.

[37] Ilbuldu, E., Cakmak, A., Disci, R., and Aydin, R. 2004. "Comparison of Laser, Dry Needling, and Placebo Laser Treatments in Myofascial Pain Syndrome." Photomed. Laser Surg. 22 (4): 306-11.

[38] Schaffer, M., Bonel, H., Spoka, R., Schaffer, P., Busch, M., Reiser, M., and Dühmke, E. 2000. "Effects of $780 \mathrm{~nm}$ Diode Laser Irradiation on Blood Microcirculation: Preliminary Findings on Time-Dependent T1-Weighted Contrast-Enhanced Magnetic Resonance Imaging (MRI)." J. Photochem. Photobiol. B 54 (1): 55-60.

[39] Han, J. 2004. "Acupuncture and Endorphins." Neurosci. Lett. 361 (1-3): 258-61. 